\section{Cureus}

Received 12/16/2015

Review began 12/17/2015

Review ended 03/24/2016

Published 04/07/2016

\section{(c) Copyright 2016}

Muneer. This is an open access article distributed under the terms of the Creative Commons Attribution License CC-BY 3.0., which permits unrestricted use, distribution, and reproduction in any medium, provided the original author and source are credited.

\title{
The Treatment of Adult Bipolar Disorder with Aripiprazole: A Systematic Review
}

\author{
Ather Muneer ${ }^{1}$ \\ 1. Psychiatry, Islamic International Medical College, Rawalpindi,Pakistan \\ $\square$ Corresponding author: Ather Muneer, muneerather2@gmail.com \\ Disclosures can be found in Additional Information at the end of the article
}

\section{Abstract}

Bipolar disorder is characterized by exacerbations of opposite mood polarity, ranging from manic to major depressive episodes. In the current nosological system of the Diagnostic and Statistical Manual $-5^{\text {th }}$ edition (DSM-5), it is conceptualized as a spectrum disorder consisting of bipolar disorder type I, bipolar disorder type II, cyclothymic disorder, and bipolar disorder not otherwise specified. Treatment of all phases of this disorder is primarily with mood stabilizers, but many patients either show resistance to the conventional mood stabilizing medications or are intolerant to their side-effects. In this setting, second-generation antipsychotics have gained prominence as many bipolar subjects who are otherwise treatment refractory show response to these agents. Aripiprazole is a novel antipsychotic initially approved for the treatment of schizophrenia but soon found to be effective in bipolar disorder. This drug is well studied, as randomized controlled trials have been conducted in various phases of bipolar disorders. Aripiprazole exhibits the pharmacodynamic properties of partial agonism, functional selectivity, and serotonin-dopamine activity modulation - the new exemplars in the treatment of major psychiatric disorders. It is the first among a new series of psychotropic medications, which now also include brexpiprazole and cariprazine. The current review summarizes the data from controlled trials regarding the efficacy and safety of aripiprazole in adult bipolar patients. On the basis of this evidence, aripiprazole is found to be efficacious in the treatment and prophylaxis of manic and mixed episodes but has no effectiveness in acute and recurrent bipolar depression.

Categories: Psychiatry

Keywords: bipolar disorder, bipolar mania, bipolar depression, mood stabilizers, third generation antipsychotics

\section{Introduction And Background}

Bipolar disorder (BD) is a common neuropsychiatric condition with a prevalence rate of approximately $4 \%$ in the general population, considering the entire bipolar spectrum [1]. It is characterized by severe disturbances in the mood of opposite polarity, which range from mania to depression. It is a chronic condition with the usual onset in adolescence or early adulthood and affects males and females equally [2]. It is highly comorbid with other diseases, such as anxiety spectrum disorders, substance abuse disorders, eating disorders, stressor-related disorders, and certain personality disorders, chiefly borderline personality disorder [3]. It can be complicated by severe depressive exacerbations, mixed episodes, rapid cycling, and subthreshold symptoms and is associated with one of the highest suicide rates among all psychiatric disorders [4]. Even after adequate treatment with currently available agents, affective episodes often fail to remit completely with persistence of symptoms and accompanying myriad complications in the biopsychosocial domain. 


\section{Cureus}

In this event, there is an unmet need for medications that are truly effective in different phases of the disorder. Unlike conventional mood stabilizers and older antipsychotics, secondgeneration antipsychotics (SGA) are multifunctional as these have shown efficacy in a broad range of psychiatric disturbances, including manic, depressive, and maintenance phases of bipolar disorder [5]. SGAs are exemplified by medications, such as risperidone, olanzapine, quetiapine, ziprasidone, and lurasidone, which are widely employed in the treatment of BD [6]. In addition to these, a new group of agents, the prototype of which is aripiprazole, is also available. The armamentarium of medications in this regard has increased with the United States Food and Drug Administration (FDA) approval of brexpiprazole and cariprazine. These are related compounds, and Figure 1 gives their chemical structures for the sake of comparison.

\section{Aripiprazole}<smiles>O=C1CCc2ccc(OCCCCN3CCN(c4cccc(Cl)c4Cl)CC3)cc2N1</smiles>

7-(4-[4-(2,3-Dichlorophenyl)piperazin-1-yl]butoxy\}-3,4-dihydroquinolin-2(1 H)-one

\section{Brexpiprazole}<smiles>O=c1ccc2ccc(OCCCCN3CCN(c4cccc5sccc45)CC3)cc2[nH]1</smiles>

7-\{4-[4-(1-benzothiophen-4-yl) piperazin-1-yl]butoxy\}quinolin-2(1H)-one

Cariprazine<smiles>CN(C)C(=O)NC1CCC(CCN2CCN(c3cccc(Cl)c3Cl)CC2)CC1</smiles>

\section{FIGURE 1: The chemical structures and IUPAC names of aripiprazole, brexpiprazole and cariprazine}

IUPAC - International Union of Pure and Applied Chemistry nomenclature

These novel agents have been variously termed "third generation antipsychotics" or "serotonin-dopamine activity modulators" and are gaining prominence in the treatment of major psychiatric ailments, such as BD, major depressive disorder (MDD), and schizophrenia. 
There are subtle but important differences in the mechanism of action of SGAs and novel antipsychotics. Whereas the former act as full antagonists or inverse agonists at the dopamine D2 receptor (D2R), the latter behave as partial agonists at this site [7]. They may have disparate activity in different areas of the brain, depending on the prevalent dopaminergic tone, and act as full antagonists in regions with high dopamine neurotransmission but as partial agonists where this trend is low [8]. Presumably, this dual action has a putative mitigating effect on positive psychotic symptoms by virtue of the dopamine-blocking action in the mesolimbic area, whereas there is alleviation of negative and cognitive symptoms because of the facilitation of dopamine transmission in the prefrontal cortex [9]. Further, novel antipsychotics purportedly act as biased ligands at the D2R, which is a G-protein-coupled receptor (GPCR). This implies that they differentially stimulate intraneuronal signal transduction pathways, in contradistinction to other antipsychotics, which do not discriminate with downstream signaling cascades. This phenomenon has been termed "functional selectivity" and may have key connotations in the treatment of main psychiatric conditions by novel antipsychotics [10].

In the case of $\mathrm{BD}$, repeated affective episodes have been shown to cause neuroinflammation, oxidative, and nitrosative stress leading to increased apoptosis of neurons in the hippocampus and other key mood-regulating areas of the brain. Administration of psychotropic drugs, like the novel antipsychotics, is neuroprotective with dendritic growth, increased synaptogenesis, and enhanced viability of neurons [11]. With the continued use of these medications, the deteriorating course of $\mathrm{BD}$, a fundamentally neuroprogressive condition, is halted and is clinically manifested as longer periods of euthymia and improved psychosocial functioning of the patients.

Aripiprazole, the forerunner of the novel antipsychotics, has been well studied in different phases of BD. This review presents a comprehensive appraisal of the extant literature, focusing on randomized controlled trials (RCT). This endeavor illuminates the role of aripiprazole in the treatment of adults with BD, a difficult to treat condition, which manifests in innumerable ways and is often refractory to the currently available psychotropic agents.

\section{Review}

\section{Search strategy}

A search of the PubMed database was conducted in October 2015 with the inclusive term “aripiprazole and bipolar." A total of 490 items were found which included reviews, case reports, pharmacokinetic investigations, clinical and preclinical studies. Narrowing the search to "clinical trials" retrieved 61 items and further refinement with "adults" resulted in 48 studies. The titles and abstracts of these papers were examined for relevance to the current topic, leading to exclusion of a further 25 studies. The rationale was to leave out records that had their main focus on other medications or psychiatric conditions. The resulting 23 studies were read in full and their reference lists consulted. Data from these papers was used to mark out the place of aripiprazole in the treatment of adults with bipolar disorder. Figure 2 illustrates the study selection process according to the PRISMA (Preferred Reporting Items for Systematic Reviews and Meta-analyses) statement. Table 1 lists the studies included in the systematic review. 


\section{Cureus}

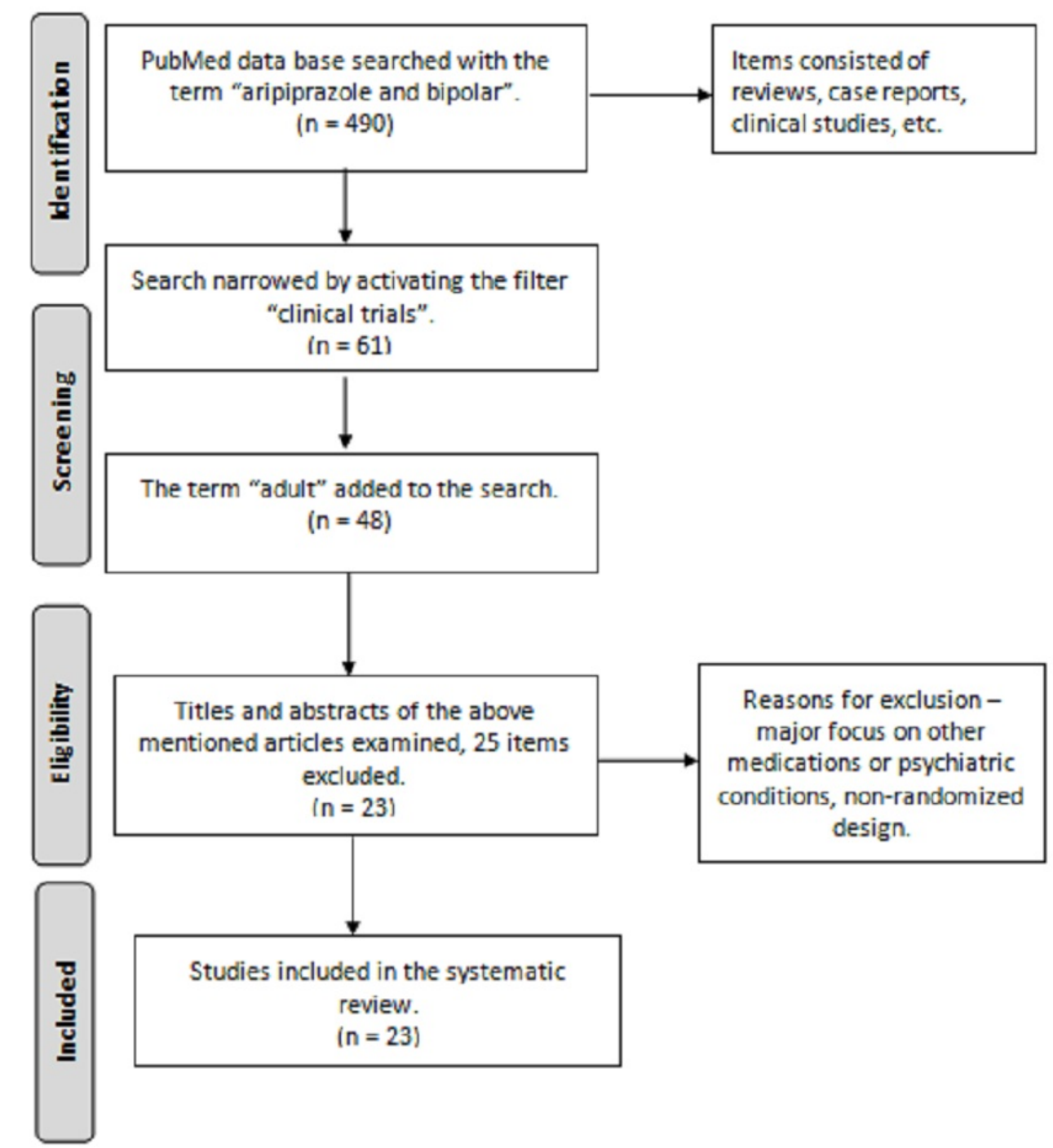

\section{FIGURE 2: Flow diagram of the systematic review}

Selection of the studies according to the PRISMA statement. PRISMA - Preferred Reporting Items for Systematic Reviews and Meta-analyses.

Study Type Methodology

\section{STUDIES IN ACUTE MANIA}

Kanba,

et al.,

2014

RCT

[27]

Jeong, et al.,
ARI (dosed from 12-24 mg/d, majority receiving $24 \mathrm{mg} / \mathrm{d}$ ) compared to PLB in this 3-week, acute phase study. Primary efficacy measure - change in YMRS score from baseline to endpoint at day 21 .

Acutely manic patients randomized to ARI + VAL or HPD + VAL and followed for 8 consecutive weeks. YMRS and CGI-S used to assess efficacy. AE monitored with Drug-
Result

ARI significantly more effective than PLB with early separation on YMRS observed from Day 4. In the ARI group, no significant metabolic derangement or prolactin elevation detected compared to PLB.

Both groups had similarly high response and remission rates. HPD associated with more 


\section{Cureus}
2012 design
[32]
induced Extrapyramidal Symptoms Scale and Liverpool University Neuroleptic Side Effect Rating Scale.

\section{EI}

Mallakh,

et al., RCT

2010

[28]

Findling,

et al.,

2009 RCT

[33]

Keck, et

al.,

$\begin{array}{ll}2009 & \text { RCT } \\ {[30]} & \end{array}$

Young,

et al.,

2009

RCT

[29]

Vieta, et

al.,

2008

RCT

[21]

Suppes,

et al., Post-hoc

2008 analysis

[34]

Sachs,
This 3-week trial conducted in BD Type I hospitalized patients with acute manic or mixed episodes. Subjects randomized to ARI, $15 \mathrm{mg} / \mathrm{d}, \mathrm{ARI}, 30 \mathrm{mg} / \mathrm{d}$, or PLB. Primary outcome parameter, change in YMRS score from baseline to day 21 .

Patients aged 10 to 17 years with acute manic or mixed episodes (with or without psychosis) randomized to ARI, $10 \mathrm{mg}, \mathrm{ARI}$, $30 \mathrm{mg}$, or PLB. Subjects followed for 4 weeks and primary efficacy measure was change in YMRS score from baseline.

A PLB and LI-controlled study, primary endpoint at Week 3. ARI and LI administered patients remained on blinded treatment for 9 additional weeks. Subjects included Bipolar I patients with acute manic or mixed episodes (YMRS $\geq 20$ ) with or without psychotic features. Primary efficacy measure change in baseline to Week 3 on YMRS for the entire study population. Secondary outcome - change in YMRS to Week 12 between ARI and LI groups.

ARI compared to HPD and PLB for the first stage of the trial ( 3 weeks). ARI evaluated against HPD for the next phase - to Week 12. YMRS employed as the psychometric instrument to assess efficacy.

Bipolar I disorder patients, current episode manic or mixed were treated with LI or VAL monotherapy. Those with non-response (YMRS $\geq 16$ ) with therapeutic blood levels, randomized to adjunctive ARI or PLB and followed up for 6 weeks. Primary efficacy measure change in YMRS score to Week 6.

Data pooled from two 3-week, flexible-dose, RCTs in BD Type I patients with index manic or mixed episodes. The patient population stratified by severity of episode (YMRS score), baseline depressive symptoms (MADRS score), and presence or absence of psychotic features/rapid cycling.

BD Type I patients with manic or mixed episodes randomized to $A R I, 30 \mathrm{mg} / \mathrm{d}$, or
EPS, while adjunctive ARI group had greater weight gain and sedative side effects.

$A R I$, both doses not significantly superior to PLB on the main efficacy measure. Compared to PLB, ARI group had notably more headache, agitation, and akathisia.

ARI (both doses) significantly superior to PLB on global improvement and overall bipolar illness outcome measures. Most common AE were EPS and somnolence. Average weight gain was not significantly different among the three groups.

Both ARI and LI significantly better than PLB on primary outcome. ARI and LI equally effective in controlling manic symptoms. ARI associated with akathisia and headache and LI with GI side effects and tremor during the trial.

ARI and HPD notably better than PLB. Both drugs maintained efficacy to Week 12. ARI superior to HPD in tolerability with fewer EPSE.

Adjunctive ARI+MS, significantly better than MS monotherapy on main outcome with separation occurring on YMRS from Week 1 onwards. Akathisia significantly more common with ARI than PLB.

ARI significantly better than PLB in patients groups with more or less severe illness, manic or mixed episodes, with or without psychotic features and rapid cycling. ARI effective in a wide array of disease characteristics associated with treatment resistance.

ARI significantly better than PLB in producing response, defined as $\geq 50 \%$ reduction in YMRS. 


\section{Cureus}

$\begin{array}{lll}\begin{array}{l}\text { et al., } \\ 2006\end{array} & \text { RCT } & \begin{array}{l}\text { PLB and studied for } 3 \text { weeks. Primary } \\ \text { efficacy measure was change in baseline } \\ \text { YMRS to endpoint. Secondary assessment } \\ \text { was with CGI-BP. }\end{array} \\ & & \begin{array}{l}\text { Bipolar I patients with acute manic or mixed } \\ \text { episodes randomized to ARI or HPD and } \\ \text { fieta, et }\end{array} \\ \text { al., } & \text { DB design. } & \begin{array}{l}\text { follow up for } 12 \text { weeks. Primary outcome } \\ \text { measure was number of patients in } \\ 2005\end{array} \\ {[31]} & & \begin{array}{l}\text { response ( } \geq 50 \% \text { reduction in YMRS) and } \\ \text { receiving treatment at endpoint. }\end{array}\end{array}$

Keck, et

al., 2003 RCT

[19]
Patients with acute manic or mixed episodes randomized to $A R I, 30 \mathrm{mg} / \mathrm{d}$, or PLB.

Primary outcome - mean change in total YMRS score from baseline to endpoint. Secondary outcome with CGI-BP.
ARI, $30 \mathrm{mg} / \mathrm{d}$, well tolerated by $85 \%$ of the patients. ARI and PLB with similar profiles on metabolic parameters, QTc interval, and serum prolactin.

Significantly more subjects in the ARI group as compared to HPD group showed response and were on treatment at Week 12. Greater discontinuation rate in the HPD group, with higher rates of EPS.

ARI significantly better than PLB on primary and secondary efficacy measures with changes observed as early as Day 4. ARI produced higher response and completion rates. ARI and PLB were statistically similar with regards to metabolic changes, QTc interval effects, and prolactin levels.

\section{CONTINUATION PHASE STUDIES IN PATIENTS WITH INDEX MANIC OR MIXED EPISODE}

Yatham,

et al., Post-hoc

2013 analysis

[37]

Carlson,

et al.,

2012

RCT

[40]

El-

Mallakh, et al., DB design.

2012

[41]

Woo, et al.,
In this study, data from a 52-week RCT was examined with regards to relapse prevention in bipolar patients with index manic or mixed episodes. Cases were initially stabilized with single-blind ARI + LI or VAL; those maintaining stability for 12 weeks were randomized to $\mathrm{ARI}+\mathrm{LI}$ or VAL or PLB + $\mathrm{LI}$ or VAL for up to 52 weeks in $\mathrm{DB}$ fashion.

Adjunctive ARI with LTG compared to LTG monotherapy in relapse prevention in BD I patients. Subjects with recent episode manic or mixed were stabilized with ARI + LTG (YMRS/MADRS $\leq 12$ ) in non-DB fashion for 9 to 24 weeks. Cases controlled for 8 consecutive weeks were randomized to ARI + LTG or PLB + LTG, DB for 52 weeks total.

Forty week continuation of a 12 week study comparing ARI and LI monotherapy in Bipolar I patients, current episode manic or mixed. Cases who maintained stability (YMRS $\leq 12$ ) in the 12-week DB study, carried on in the same manner for a total of 52 weeks. Outcome parameters were mean change in total YMRS and MADRS scores from baseline to Week 52, with results reported for observed cases only.

BD Type I patients, current episode manic or mixed stabilized with ARI + VAL for 6 weeks in an open-label manner. Those meeting
Pooled data showed that adjunctive ARI significantly superior to PLB in relapse prevention in patients with manic but not mixed episodes. ARI + MS produced significant reductions in YMRS scores in both populations. Adjunctive ARI may be a more appropriate maintenance treatment for bipolar subjects with recurrent manic episodes.

ARI + LTG not statistically superior to LTG alone, in delaying time to manic or mixed relapse. NNT/NNH ratio was 9/22. Akathisia, anxiety, and insomnia more frequent in the ARI + LTG versus PLB + LTG group.

A high drop-out rate in both groups. ARI alone and $\mathrm{LI}$ alone, equally effective in relapse prevention in Bipolar I patients with index manic or mixed episode. More frequent AE with ARI included akathisia, headache, somnolence, and anxiety. On metabolic parameters, no significant difference between the two treatments.

Relapse rate less with adjunctive ARI than with VAL monotherapy, but this observation did not 


\section{Cureus}
2011 RCT
[39]
Marcus,
et al.,
2011
RCT
[22]
Vieta, et
Open-label
continuation
al., of acute
2010
[38]
phase
adjunctive
$A R I$ versus
PLB study.
stabilization criteria followed up for 24 weeks in $D B$ way receiving $A R I+V A L$ or PLB + VAL.
BD Type I patients, recent episode manic or mixed treated with open-label LI or VAL for at least 2 weeks. Non-responders (YMRS $\geq$ 16) administered adjunctive $A R I$ in non-DB fashion. Those achieving stabilization with this regimen (YMRS and MADRS $\leq 12$ ) for 12 successive weeks randomized to $A R I+L I$ or VAL or PLB + LI or VAL, DB and followed up for 52 weeks.
Completers of a 6-week DB ARI + LI or VAL versus $\mathrm{PLB}+\mathrm{LI}$ or VAL trial could continue with open-label ARI + LI or ARI + VAL for further 46 weeks. The purpose of the study was to compare the efficacy, safety, and tolerability of ARI + LI versus ARI + VAL in the continuation phase.

al.,

2006

RCT

[36]

BD I patients current episode manic or mixed and hospitalized for treatment were stabilized (YMRS $\leq 10 /$ MADRS $\leq 13$ for 6 successive weeks) with open-label ARI, 15 or $30 \mathrm{mg} / \mathrm{d}$. They were subsequently randomized to ARI or PLB, DB for the total study duration of 26 weeks. Primary
Keck, et endpoint defined as discontinuation due to precipitation of any episode - manic, mixed, or depressive.

\section{MAINTENANCE PHASE STUDIES}

Keck, et

al., 2007 RCT

Muzina, et al., Post-hoc 2008 analysis [42]
Firstly, patients with index manic or mixed episodes were stabilized (YMRS $\leq 10$, MADRS $\leq 13$ for 6 consecutive weeks) with open-label ARI (15 or $30 \mathrm{mg} / \mathrm{d}$ ). Stabilized patients were randomized to ARI or PLB, DB and followed for 26 weeks. Cases who maintained remission at the end of this period were studied for further 74 weeks (total duration 100 weeks) in a similar manner.

Rapid cycling BD is difficult to treat as continued remission is hard to achieve. In the 100 week maintenance study, rapid cycling patients were identified (total $=28$, $A R I=14, P L B=14)$. Twelve (ARI = 7, PLB = 5) completed the 26 -week phase. Only 3 reach statistical significance. No serious adverse events noted with ARI + VAL combination.

Adjunctive ARI + MS significantly better than MS monotherapy in delaying time to any relapse. AE more common in the ARI group were tremor, headache, insomnia, and weight gain.

High attrition rates in the two groups. Using LOCF, both groups maintained significant improvements in total YMRS and MADRS scores during the open-label continuation period. Most frequent AEs in the two groups included tremor, akathisia, headache, insomnia, and weight gain.

ARI, 15 or $30 \mathrm{mg} / \mathrm{d}$, significantly better than PLB in prolonging time to manic but not depressive relapse. Adverse effects (reported in $\geq 5 \%$ of patients and twice the rate of PLB) were akathisia, tremor, extremity pain, and vaginitis. Weight gain occurred in ARI monotherapy group (13\%) but not in the PLB group.

Cases in remission inducted in the extension phase and treated with ARI showed a statistically significant longer time to manic relapse but not to depressive relapse. AE in ARI group observed in $\geq 5 \%$ of the subjects and twice the rate of PLB were tremor, akathisia, dry mouth, hypertension, weight gain, vaginitis, abnormal thinking, pharyngitis, and flu syndrome. The weight increase in the ARI treated patients (LOCF) over the 100 weeks was of small magnitude +0.4 (range: $+/-0.8) \mathrm{kg}$.

In rapid cycling Bipolar I patients with index manic or mixed episode, ARI significantly superior to PLB in delaying time to relapse in both the initial and extension phases of the study. This demands further research with prospectively designed and adequately powered 


\section{Cureus}

finished the 100 week period (all ARI group). trials.

\section{STUDIES IN BIPOLAR DEPRESSION}

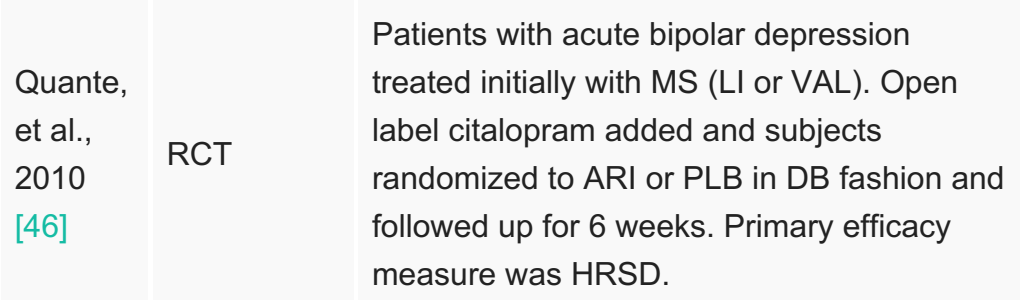

Two similarly designed, multicenter, 8-week, monotherapy trials of ARI versus PLB in Bipolar I outpatients experiencing MDE Thase, without psychotic features were conducted. et al., $\quad$ ARI initiated at $10 \mathrm{mg} / \mathrm{d}$, then flexibly dosed 2008 from 5 to $30 \mathrm{mg} / \mathrm{d}$ based on clinical effect [45]

Thase, et al., Post- hoc 2011 analysis and tolerability. Primary efficacy measure was change in total MADRS score from baseline to Week 8. Secondary outcome was with CGI-BP.

Patients in the above-mentioned two studies were stratified according to the severity of core depressive symptoms at baseline using the Bech-Rafaelsen subscale. Bech- 6 total score $>15$, more severely depressed; Bech6 total score $<15$, less severely depressed. Efficacy of the active agent was evaluated employing changes in MADRS total and MADRS- 6 subscale scores from baseline to Week 8.

Adjunctive ARI no better than PLB on primary efficacy measure and there was no significant difference between both groups at any point. Lack of additional benefit with ARI attributable to already good effectiveness of the control group because of treatment with citalopram.

At endpoint, ARI failed to separate from PLB on both primary and secondary efficacy measures. ARI group suffered from greater rates of akathisia, insomnia, nausea, fatigue, restlessness, and dry mouth. Discontinuation rates higher with ARI than PLB.

Those classified as more severely depressed at the initial presentation had greater reduction in depression scores with ARI than PLB and this change reached statistical significance. The post-hoc analysis showed that sub-sets of patients with more severe core depressive symptoms at baseline benefited from ARI monotherapy.

\section{TABLE 1: Studies Evaluating Efficacy and Safety of Aripiprazole in Different Phases of Bipolar Disorder}

AE - adverse events; ARI - aripiprazole; BD - bipolar disorder; DB - double blind; CGI-BP - Clinical Global Impressions scale- Bipolar Version; EPS -extrapyramidal symptoms; HRSD - Hamilton Rating Scale for Depression; HPD - haloperidol; LI -lithium; LOCF - last observation carried forward; LTG - lamotrigine; MADRS - Montgomery-Asberg depression rating scale; MS - mood stabilizer; NNT number needed to treat; NNH - number needed to harm; PLB - placebo; RCT - randomized controlled trial; VAL - divalproex sodium; YMRS - Young Mania Rating Scale.

\section{Pharmacology of aripiprazole}

\section{Pharmacokinetic Data}

The drug is available in oral form and in an intramuscular formulation for acute administration for the rapid control of agitated psychotic behavior. More recently, a long-acting injectable composition has been approved by the FDA for the maintenance treatment of schizophrenia. The orally taken drug is well absorbed with a bioavailability of $87 \%$ and can be used without regards to ingestion of food. It shows linear pharmacokinetics at therapeutic doses with peak 
plasma concentrations reached between three to five hours after intake. Aripiprazole has a long half-life of approximately 75 hours so that patients can still maintain therapeutic blood levels even if they forget to take it in the short term [12]. Steady state plasma levels are achieved after about 14 days of continuous administration. It is extensively metabolized in the liver by cytochrome P450 (CYP) 2D6 and 3A4 isoenzymes. The former is responsible for dehydrogenation and hydroxylation and the latter for dealkylation of the drug. Dehydroaripiprazole is the active metabolite of the drug and has an even longer half-life of 96 hours. Aripiprazole does not induce or inhibit CYP450 enzymes and, therefore, causes no interference with the elimination of other medications. However, subjects who are deficient in CYP2D6 (8\% of Caucasians) have about a 60\% higher blood concentration of aripiprazole, and in such individuals, the half-life of the compound approximately doubles [13]. The selective serotonin reuptake inhibitor, paroxetine, is a strong inhibitor of CYP2D6 and greatly reduces the hepatic clearance of aripiprazole. Likewise, inducers (e.g., carbamazepine) or inhibitors (e.g., fluvoxamine) of CYP3A4, respectively, decrease or increase serum aripiprazole levels.

\section{Pharmacodynamic Data - Dopamine D2 Receptor Binding}

Aripiprazole is a partial agonist at dopamine D2R; it has a high affinity for this site and, at therapeutic doses, occupies approximately 95\% of D2R in the striatum. However, it shows low intrinsic activity at this receptor and causes much lower activation of the D2R compared to the endogenous ligand, dopamine [14]. The key notion put forward is that it acts as a full antagonist at D2R when the synaptic concentration of dopamine is high and as a partial agonist when this value is low. Taking together its high affinity and partial agonism at D2R, it supposedly antagonizes the burst firing of dopaminergic neurons, explaining its therapeutic effects; at the same time, it allows tonic activity of this neurotransmitter, resulting in a low incidence of extrapyramidal side effects (EPSE). The consequence of this mechanism may be an overall reduction in dopamine activity in the mesolimbic region of the brain while there is a maintenance of stimulant effect in the mesocortical and nigrostriatal areas [15].

\section{Functional Selectivity/Biased Ligand Pharmacology}

D2R is a G-protein-coupled receptor, and ligand binding results in downstream signaling via inhibition of adenyl cyclase. However, experiments in rodents have shown that D2R-mediated effects can occur independently of this mechanism through the scaffolding protein, $\beta$-arrestin 2. The latter associates with protein kinase B (Akt) and protein phosphatase $2 \mathrm{~A}$, causing activation of glycogen synthase kinase-3 (GSK-3); $\beta$-arrestin 2/Akt/GSK-3 signaling is implicated in major psychiatric disorders, including BD and schizophrenia [16]. Drugs like aripiprazole can have a differential effect on GPCR and, acting as a biased ligand, can discerningly activate one or the other pathway depending on receptor conformation. The supposed functional selectivity at GPCR by agents like aripiprazole, brexpiprazole, and cariprazine have given novel perspective to the treatment of hitherto intractable mental conditions and will undoubtedly be a principal focus for the development of better and more effective psychotropic medications [17]. Figure 3 schematically illustrates key concepts in this pharmacodynamic model. 


\section{Cureus}

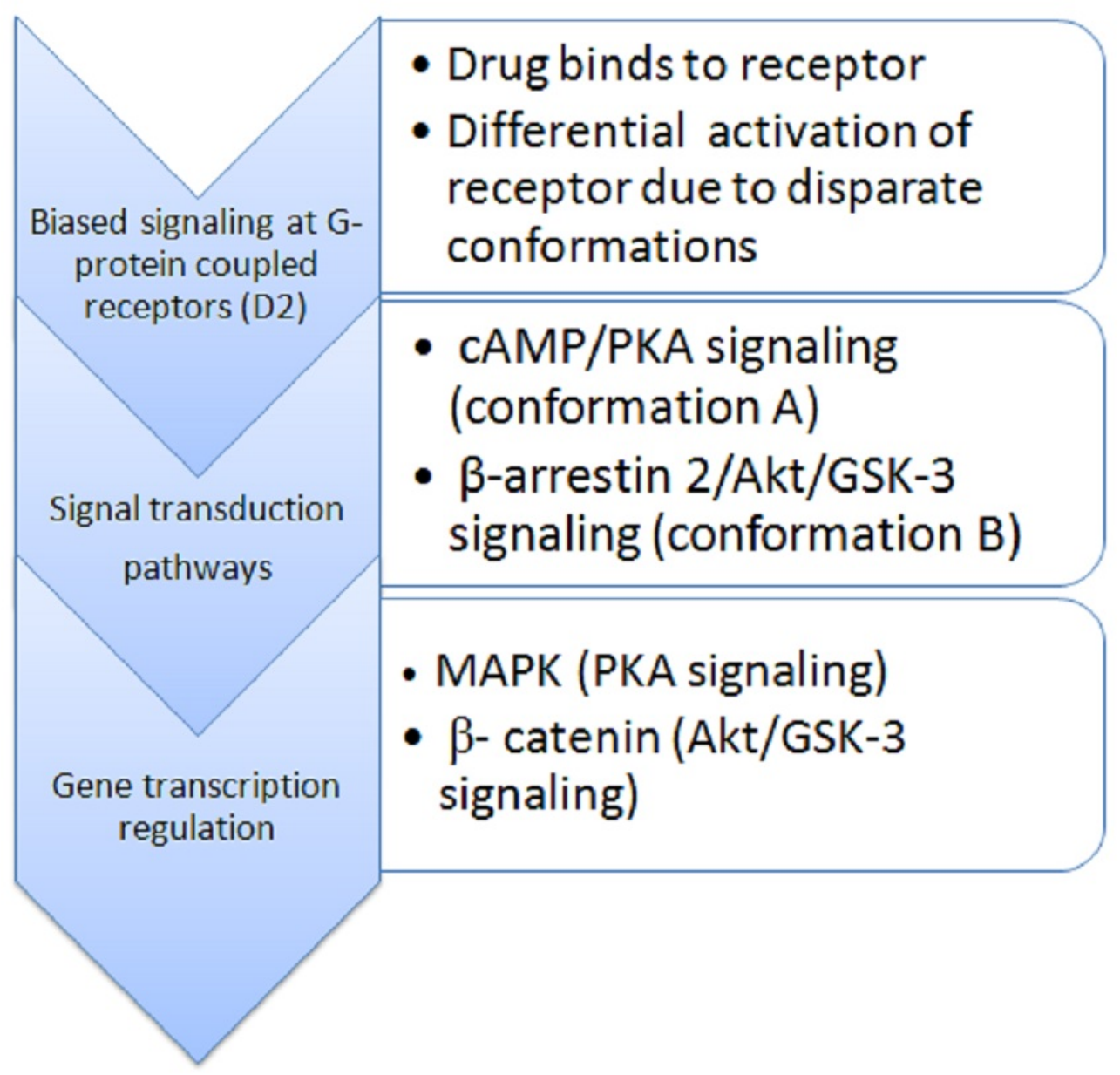

FIGURE 3: Purported mechanism of biased signaling by novel antipsychotics

Biased ligands are presumed to act in a functionally discriminating manner at G-protein-coupled receptors, e.g. D2-type. One method of functional selectivity may be the favored binding to diverse conformations of the receptor, activating different downstream pathways according to the local milieu and the neuronal subtypes in which these are expressed. Postsynaptic scaffolding proteins, adaptors, and effectors may be discrepantly affected by each receptor conformation-related cascade differentially stimulated by the ligand.

Akt - protein kinase B; cAMP - cyclic adenosine monophosphate; GSK-3 - glycogen synthase kinase-3; MAPK - mitogen-activated protein kinase; PKA- protein kinase A.

Other Receptor Interactions of Aripiprazole

In several in vitro experiments, aripiprazole has performed as a partial agonist at 5HT1A receptors, whereas other data suggest that it acts as an agonist at the somatodendritic 5HT1A autoreceptors found in the dorsal raphe serotonergic neurons. The latter has major projections to the prefrontal cortex and decreased serotonergic firing mediated by the activation of 5HT1A autoreceptors, in turn, causes an increase in the dopaminergic tone. Working through this mechanism, aripiprazole may improve cognitive and negative symptoms in bipolar spectrum disorders and schizophrenia. In this vein, brexpiprazole and aripiprazole have been more aptly described as "serotonin-dopamine activity modulators" [18]. Further, aripiprazole has been shown to act as an agonist at $5 \mathrm{HT} 2 \mathrm{C}$ receptors and this action has been regarded as 
advantageous in decreasing appetite and avoiding antipsychotic-induced weight gain. 5HT2A antagonism is a property that aripiprazole shares with other SGAs and the ramifications of this interaction embrace a reduction in EPSE during therapy with these agents. Finally, it only moderately blocks the alpha 1 adrenergic and histamine $\mathrm{H} 1$ receptors, which may account for the low incidence of orthostatic hypotension and sedation with the use of this compound.

\section{Tolerability and safety}

Data from short and long-term studies in bipolar subjects indicates that aripiprazole has a good tolerability and safety profile. During the acute three-week monotherapy trials, the most commonly noted adverse effects versus placebo were akathisia (13\% vs. $4 \%$ ), sedation ( $8 \%$ vs. $3 \%$ ), restlessness (6\% vs. 3\%), tremor (6\% vs. 3\%), and EPSE (5\% vs. 2\%) [19-20]. In a six-week study of aripiprazole adjunctive to mood stabilizers, akathisia (19\% v. 5\%), insomnia (8\% v. 4\%), and extrapyramidal side effects (5\% vs. $1 \%$ ) were most frequently described [21]. Two recurrence prevention trials for 52 and 100 weeks showed tremor, akathisia, hypertension, and dry mouth to be the common side effects [22-23]. Across the long-term trials, the most common treatment-emergent adverse events that lead to treatment discontinuation in aripiprazole recipients were mania (1\%) or manic reaction (7\%), akathisia (5\%), and tremor (2\%).

\section{Extrapyramidal Side Effects}

Apparently because of aripiprazole's low intrinsic activity and partial agonism at D2R, there is a sustained stimulating effect of the endogenous ligand, dopamine, in the nigrostriatal pathway accounting for fewer EPSE with its use. The most commonly reported adverse events are akathisia and tremor while the rest of the EPSE-like dystonias, pseudo-parkinsonism, and tardive dyskinesias are conspicuously uncommon. When EPSE occur, these are generally of mild to moderate nature, translating into a low discontinuation rate for aripiprazole because of these side-effects.

\section{Metabolic Effects}

Bipolar disorder is viewed as a systemic illness with such manifestations as obesity, serum lipid abnormalities, and diabetes. Many atypical antipsychotics have the liability to cause or aggravate the metabolic syndrome, which is marked by increased body mass index, dyslipidemia, and glucose intolerance. According to a comprehensive literature review, among the SGAs, clozapine, olanzapine, quetiapine, and risperidone emerge as the worst offenders, whereas aripiprazole appears to have the fewest adverse metabolic effects [24]. The safety of aripiprazole in bipolar subjects is borne out by a post-hoc analysis of a 26-week study, which shows rates of metabolic syndrome with aripiprazole comparable to placebo [25]. According to the data from controlled short and long-term studies, there are no significant negative effects of aripiprazole mono or adjunctive therapy on such parameters as serum cholesterol, triglycerides, or glucose.

\section{Effect on Prolactin Secretion}

The discharge of dopamine from the hypothalamus is a signal for the anterior pituitary gland to prohibit the release of prolactin, and antipsychotics, which strongly bind to D2 receptors like haloperidol and risperidone, let go of this control by acting as antagonists. Contrarily, aripiprazole, a partial agonist at the D2R, appears to facilitate dopamine transmission in the tuberoinfundibular pathway and prevents hyperprolactinemia from occurring. Raised serum prolactin is associated with such untoward effects as sexual dysfunction, amenorrhea, galactorrhea, and bone demineralization. There is evidence that aripiprazole therapy may perhaps be associated with an overall decline in the serum prolactin level in bipolar patients 
who switch from other antipsychotics to this medication [26].

Effect on Electrocardiogram (ECG)

Some psychotropic medications, including antipsychotics such as thioridazine and ziprasidone, are associated with prolongation of the corrected QT (QTc) interval, which can potentially lead to such lethal arrhythmias as torsades de pointes. As far as aripiprazole is concerned, evidence from studies in bipolar patients shows that it has no such untoward effect and does not cause QTc prolongation [26].

\section{Studies in bipolar mania}

Acute Manic Phase Studies

The efficacy of aripiprazole monotherapy in the treatment of acute mania has been studied in at least four RCTs. According to the existing literature, the most recent study was a multicenter, double-blind trial of Japanese patients, which investigated the efficacy and safety of aripiprazole ( $24 \mathrm{mg} /$ day) versus placebo for three weeks. Statistically significant mean improvements were noted from Day 4 onwards to Day 21 (-11.3 vs. -5.3 on Young Mania Rating Scale [YMRS]) at endpoint [27]. These results were in line with two earlier key trials of aripiprazole, $30 \mathrm{mg}$, versus placebo conducted mainly in Caucasian populations [19-20]. In an RCT, Bipolar I patients with acute manic or mixed episodes were randomized to two fixed doses of aripiprazole (15 or $30 \mathrm{mg} / \mathrm{d}$ ) or placebo. In this three-week trial, both of the active agent groups were not statistically better than placebo on the primary efficacy measure of YMRS at endpoint [28].

In a well-powered trial, both aripiprazole and haloperidol showed a significantly greater mean change in the YMRS compared to placebo at Week 3 with equivalent improvements for the two medications at Week 12 [29]. In another study evaluating aripiprazole, lithium, and placebo for three and 12-week periods, aripiprazole showed significant improvement in the mean YMRS score within two days. This improvement carried on over three weeks and was sustained over 12 weeks in an analogous manner for both drugs [30]. In another trial, more acutely manic patients were in remission and taking aripiprazole compared to haloperidol at the study endpoint at Week 12 [31]. In summary, in these trials, which compared aripiprazole (doses of 15-30 mg) to established standard antimanic treatments, there was an equivalent efficacy of the active agents. Additionally, using YMRS scores as the benchmark, corresponding early and continued separation from placebo was noted and remission rates were achieved at three and 12 weeks, with the advantage of proportionately lower drop-outs in subjects taking aripiprazole.

In an RCT, aripiprazole showed additional benefits adjunctive to lithium or valproate in acute manic and mixed episodes. Bipolar I patients with acute mania partially nonresponsive to the mood stabilizer alone and receiving combined treatment with aripiprazole and one of the mood stabilizers demonstrated a significantly higher reduction of their baseline YMRS score at Week 6 versus placebo (at study endpoint: -13.3 for aripiprazole, -10.7 for placebo). In this trial, similar to the monotherapy studies, significant improvement in YMRS total score was noted with aripiprazole versus placebo from Week 1 onward [21]. In a study, both adjunctive aripiprazole and haloperidol with the first-line mood stabilizer, divalproex sodium, were equally efficacious in acute bipolar mania; the novel antipsychotic was associated with fewer EPSE as compared to haloperidol but caused greater weight gain and sedation [32]. In subjects aged 10 to 17 years and presenting with acute manic or mixed episodes, aripiprazole monotherapy was statistically superior to placebo in inducing remission, was well-tolerated, and did not result in any significant weight gain [33]. A post-hoc analysis of two short-term, three-week monotherapy trials of subjects with BD Type I experiencing acute manic or mixed 


\section{Cureus}

episodes is instrumental in elucidating the efficacy of this medication across a wide range of illness characteristics associated with treatment resistance. The data was stratified according to the severity of manic symptoms, the presence of depressive features, psychosis, and history of rapid cycling. The salutary effects of aripiprazole therapy were seen in these different subsets of cases with severe disease attributes, epitomizing that this agent has an important place in the treatment of bipolar diathesis [34]. Finally, while this article was in revision, a published meta-analysis showed that in both controlled and real-world settings, aripiprazole was superior to placebo and equal to active comparators in acute and stabilization phases of bipolar mania. Its safety profile was similar to other antipsychotics when considering such side effects as sedation, akathisia, EPSE, and weight gain but had a notably lower tendency to cause hyperprolactinemia [35].

The data presented above is further explained in Table 2 .

\begin{tabular}{|c|c|c|c|c|}
\hline Study & $\begin{array}{l}\text { Rescue } \\
\text { medications }\end{array}$ & Design & Subjects & Primary outcome \\
\hline $\begin{array}{l}\text { Keck, et } \\
\text { al., } \\
2003 \\
{[19]}\end{array}$ & $\begin{array}{l}\text { Lorazepam, } \\
\text { benztropine }\end{array}$ & $\begin{array}{l}\text { DB, 3-week primary endpoint, ARI } 30 \\
\text { mg/day fixed-dose (could be reduced to } \\
15 \text { mg/day) }\end{array}$ & $\begin{array}{l}262 \text { subjects with acute } \\
\text { manic or mixed } \\
\text { episodes, mean YMRS } \\
\text { at baseline } 28.2 \text { (ARI) } \\
\text { and } 29.7 \text { (PLB) }\end{array}$ & $\begin{array}{l}\text { YMRS reduction: - } \\
8.2 \text { (ARI), }-3.4 \\
\text { (PLB), } p \leq 0.002\end{array}$ \\
\hline $\begin{array}{l}\text { Sachs, } \\
\text { et al., } \\
2006 \\
\text { [20] }\end{array}$ & $\begin{array}{l}\text { Lorazepam, } \\
\text { benztropine }\end{array}$ & $\begin{array}{l}\text { DB, 3-week primary endpoint, ARI } 30 \\
\text { mg/day fixed-dose (could be reduced to } \\
15 \text { mg/day) }\end{array}$ & $\begin{array}{l}272 \text { subjects with acute } \\
\text { manic or mixed } \\
\text { episodes, mean YMRS } \\
\text { at baseline } 28.8 \text { (ARI) } \\
\text { and } 28.5 \text { (PLB) }\end{array}$ & $\begin{array}{l}\text { YMRS reduction: - } \\
12.5(\mathrm{ARI}),-7.2 \\
\text { (PLB), } p \leq 0.001\end{array}$ \\
\hline $\begin{array}{l}\text { Kanba, } \\
\text { et al., } \\
2014 \\
{[27]}\end{array}$ & $\begin{array}{l}\text { Short-acting } \\
\text { benzodiazepines, } \\
\text { biperiden }\end{array}$ & $\begin{array}{l}\text { DB, 3-week primary endpoint, ARI } 24 \\
\text { mg/day fixed-dose (could be reduced to } \\
12 \mathrm{mg} / \text { day) }\end{array}$ & $\begin{array}{l}258 \text { subjects with acute } \\
\text { manic or mixed } \\
\text { episodes, mean YMRS } \\
\text { at baseline } 28.3 \text { (ARI) } \\
\text { and } 28.0 \text { (PLB) }\end{array}$ & $\begin{array}{l}\text { YMRS reduction: - } \\
11.3 \text { (ARI), }-5.3 \\
\text { (PLB), } p \leq 0.001\end{array}$ \\
\hline $\begin{array}{l}\text { El } \\
\text { Mallakh, } \\
\text { et al., } \\
2010 \\
{[28]}\end{array}$ & $\begin{array}{l}\text { Lorazepam, } \\
\text { benztropine }\end{array}$ & $\begin{array}{l}\text { DB, 3-week primary endpoint. ARI } 30 \\
\text { mg/day or } 15 \text { mg/day fixed-dose }\end{array}$ & $\begin{array}{l}401 \text { subjects with acute } \\
\text { manic or mixed } \\
\text { episodes, mean YMRS } \\
\text { at baseline } 27.9 \text { (ARI } 15 \\
\text { mg), } 27.3 \text { (ARI } 30 \mathrm{mg} \text { ), } \\
28.3 \text { (PLB) }\end{array}$ & $\begin{array}{l}\text { YMRS reduction: - } \\
10.0 \text { (ARI } 15 \mathrm{mg}),- \\
10.8 \text { (ARI } 30 \mathrm{mg}),- \\
10.1 \text { (PLB), } p=\text { not } \\
\text { significant }\end{array}$ \\
\hline $\begin{array}{l}\text { Young, } \\
\text { et al., } \\
2009 \\
\text { [29] }\end{array}$ & $\begin{array}{l}\text { Benzodiazepines, } \\
\text { anticholinergics } \\
\text { for EPSE, } \\
\text { propranolol for } \\
\text { tremor or } \\
\text { akathisia }\end{array}$ & $\begin{array}{l}\text { DB, 3-week primary endpoint, ARI 15-30 } \\
\text { mg/day, HAL 5-15 mg/day flexible } \\
\text { dosing. DB continuation of ARI and HAL } \\
\text { until Week } 12 \text { (secondary endpoint) }\end{array}$ & $\begin{array}{l}485 \text { subjects with acute } \\
\text { manic or mixed } \\
\text { episodes, mean YMRS } \\
\text { at baseline } 28.4 \text { (ARI), } \\
28.0 \text { (HAL), } 28.8 \text { (PLB) }\end{array}$ & $\begin{array}{l}\text { YMRS reduction at } \\
\text { week } 3:-12.0(A R I) \text {, } \\
-12.8(\mathrm{HAL}),-9.7 \\
(\mathrm{PLB}) . p=0.039 \text { for } \\
\text { ARI and } p \leq 0.005 \\
\text { for HAL }\end{array}$ \\
\hline $\begin{array}{l}\text { Keck, et } \\
\text { al., } \\
2009\end{array}$ & $\begin{array}{l}\text { Benzodiazepines, } \\
\text { benztropine, }\end{array}$ & $\begin{array}{l}\text { DB, 3-week primary endpoint, ARI 15-30 } \\
\text { mg/day, LI 900-1500 mg/day flexible } \\
\text { dosing. DB continuation of ARI and LI }\end{array}$ & $\begin{array}{l}480 \text { subjects with acute } \\
\text { manic or mixed } \\
\text { episodes, mean YMRS }\end{array}$ & $\begin{array}{l}\text { YMRS reduction at } \\
\text { week 3: }-12.6(\mathrm{ARI}) \text {, } \\
-12.0(\mathrm{LI}),-9.0 \\
(\mathrm{PLB}) . p \leq 0.001 \mathrm{for}\end{array}$ \\
\hline
\end{tabular}




\section{Cureus}

[30] propranolol

until Week 12 (secondary endpoint)

DB, 6-week primary endpoint. ARI

Vieta, et

al.,

2008

[21]
Benzodiazepines, anticholinergics, propranolol adjustable dose $30 \mathrm{mg} /$ day or $15 \mathrm{mg} /$ day

or PLB add on to LI or VAL. Partial non-

responders with a YMRS $\geq 16$ after 2

weeks of LI or VAL with therapeutic

plasma levels at baseline 28.5 (ARI),

29.4 (LI), 28.9 (PLB)

ARI and $p=0.005$

for LI

384 subjects with acute

manic or mixed

episodes, mean YMRS

at baseline 23.1 (ARI),

22.7 (PLB)
YMRS reduction: -

13.3 (ARI), -10.7

(PLB), $p \leq 0.01$

\section{TABLE 2: RCTs of Aripiprazole in Acute Mania}

Abbreviations: ARI - aripiprazole, DB - double blind, EPSE - extrapyramidal side-effects, HAL - haloperidol, LI - lithium, PLB placebo, RCT - randomized controlled trial, VAL - valproate, YMRS - Young Mania Rating Scale.

Continuation Phase Studies in Patients with Index Manic or Mixed Episodes

The safety and efficacy of aripiprazole have been studied in RCTs in the continuation phase following treatment of acute manic or mixed episodes in Bipolar I disorder. In a placebocontrolled monotherapy trial, hospitalized bipolar patients with manic or mixed episodes were initially given open-label aripiprazole (15 or $30 \mathrm{mg} / \mathrm{d}$ ). Those who achieved sustained remission (YMRS $\leqslant 10 ;$ MADRS $\leqslant 13$ ) for at least six weeks were assigned to either placebo or aripiprazole in a double blind way and followed for the total study duration of 26 weeks. It was determined that the active treatment (both doses) was statistically significant compared to placebo in delaying time to manic, but not depressive, relapse and was relatively well tolerated with a low incidence of side effects [36].

A 52-week trial evaluated the safety and efficacy of aripiprazole + lithium or valproate versus placebo + lithium or valproate in manic subjects who had an inadequate response to mood stabilizer monotherapy during at least two weeks of treatment. Aripiprazole was added in a non-double blind mode and those patients who became stable for 12 consecutive weeks (YMRS and MADRS scores $\leqslant 12$ ) were randomized to the active drug or placebo and followed in a double-blind manner for a total of 52 weeks. The results showed that, evaluated against the placebo, significantly more patients who responded to add-on aripiprazole in the acute manic or mixed phase remained relapse-free with the active drug during the continuation phase. This finding suggested that there was a long-term benefit in continuing aripiprazole adjunctive to the first-line mood stabilizers for relapse prevention of manic and mixed episodes, once sustained remission was achieved with the combination regimen in Bipolar I disorder patients [22]. A post-hoc analysis of a 52-week double-blind, placebo-controlled trial of adjunctive aripiprazole and first-line mood stabilizers in Bipolar I patients with initial manic or mixed episodes showed that this agent was more effective in preventing relapses in those with index manic, as compared to mixed episodes [37].

In a 52-week study, completers of a six-week double-blind comparison of adjunctive aripiprazole versus placebo in bipolar mania who were only partially responsive to previous lithium or valproate monotherapy could enter a 46-week extension with open-label aripiprazole + lithium or aripiprazole + valproate. Using the last observation carried forward to account for drop-outs, it was noticed that statistically significant improvement from baseline over the 52 weeks occurred with aripiprazole + lithium/valproate on the mean YMRS and Montgomery-Asberg Depression Rating Scale (MADRS) total scores. In summary, this open- 


\section{Cureus}

label study demonstrated that long-term aripiprazole in conjunction with traditional mood stabilizers was efficacious in the prophylaxis of manic or mixed episodes, maintained the functioning of bipolar patients, and had a good safety and tolerability profile [38]. A continuation phase RCT in Korean patients could not replicate these findings. In this 24-week study, adjunctive aripiprazole and lithium or valproate were not statistically better than placebo + mood stabilizer in preventing affective recurrences [39]. In a long-term trial, aripiprazole + lamotrigine was not significantly superior to placebo + lamotrigine in delaying time to affective relapse in Bipolar I patients [40].

Lastly, in a long-term 52-week study, aripiprazole and lithium were analyzed head-to-head in a double-blind manner. In the stabilization phase, Bipolar I disorder subjects with initial manic or mixed episodes were treated double-blind with the above-mentioned medications for 12 weeks. Those who achieved sustained remission (YMRS and MADRS scores $\leqslant 12$ ), were followed in the same manner for a further period of 40 weeks. Statistics were drawn on observed cases only, and although there was a high attrition rate, the completers of the study had equivalent benefit in the prevention of manic and mixed episodes. In contrast to lithium, data showed that aripiprazole was better tolerated with fewer and less severe adverse events [41].

A summary of the key long-term trials of aripiprazole in BD is provided in Table 3.

\begin{tabular}{|c|c|c|c|c|c|}
\hline Study & Design & Subjects & Outcome & Adverse events & Conclusion \\
\hline $\begin{array}{l}\text { El- } \\
\text { Mallakh, } \\
\text { et al., } \\
2012 \\
{[41]}\end{array}$ & $\begin{array}{l}\text { DB. After initial } \\
\text { randomization to } 12 \\
\text { weeks of LI vs. ARI } \\
\text { monotherapy, patients } \\
\text { continued to receive either } \\
\text { ARI } 15-30 \mathrm{mg} / \mathrm{day} \text { or LI } \\
900,1200 \text { or } 1500 \mathrm{mg} / \text { day } \\
\text { for further } 40 \text { weeks. }\end{array}$ & $\begin{array}{l}66 \text { patients } \\
\text { with index } \\
\text { manic or } \\
\text { mixed } \\
\text { episodes } \\
\text { entered the } \\
\text { extension } \\
\text { phase. Only } \\
20 \\
\text { completed } \\
\text { the entire } \\
\text { phase (ARI } \\
n=7 \text {; LI } n= \\
\text { 13). Efficacy } \\
\text { endpoints } \\
\text { included } \\
\text { adjusted } \\
\text { mean } \\
\text { change from } \\
\text { baseline to } \\
\text { week } 52 \text { in } \\
\text { YMRS and } \\
\text { MADRS } \\
\text { total scores. }\end{array}$ & $\begin{array}{l}\text { Remission defined as } \\
\text { YMRS total score } \leq \\
\text { 12. Significant } \\
\text { improvement that } \\
\text { occurred over the first } \\
12 \text { weeks was } \\
\text { maintained over the } \\
40 \text { weeks of } \\
\text { continuation. }\end{array}$ & $\begin{array}{l}\text { ARI - akathisia, } \\
\text { headache, } \\
\text { somnolence, anxiety, } \\
\text { and nasopharyngitis } \\
\text { (all } 8 \%) . \mathrm{LI} \text { - insomnia } \\
(15.8 \%) \text {, headache } \\
(13.2 \%) \text {, diarrhea } \\
(13.2 \%) \text {, and vomiting } \\
(10.5 \%) . \text { Mean weight } \\
\text { change }+2.71 \mathrm{~kg} \text { for LI } \\
\text { and }+5.66 \mathrm{~kg} \text { for ARI, } \\
p=0.46\end{array}$ & $\begin{array}{l}\text { ARI monotherapy } \\
\text { equivalently } \\
\text { efficacious to LI } \\
\text { for extended } \\
\text { treatment of BD } \\
\text { patients with } \\
\text { index manic or } \\
\text { mixed episodes. } \\
\text { ARI better } \\
\text { tolerated than LI } \\
\text { in the long term. }\end{array}$ \\
\hline & $\begin{array}{l}\text { Patients with a manic or } \\
\text { mixed episode received } \mathrm{LI}\end{array}$ & & & & $\begin{array}{l}\text { Continuation of } \\
\text { ARI + LI/VAL } \\
\text { treatment } \\
\text { increased time to } \\
\text { relapse to any }\end{array}$ \\
\hline
\end{tabular}




\section{Cureus}

or VAL for at least 2

weeks. Those with an

inadequate response

[YMRS total score $\geq 16$

Marcus, and $\leq 35 \%$ decrease from

2011 received single-blind ARI

[22] + MS. Patients who and MADRS score $\leq 12$ ]

for 12 consecutive weeks were randomized to $\mathrm{DB}$

ARI (10-30 mg/day) or

PLB + LI/VAL for 52 weeks. et al., baseline at week 2] achieved stability [YMRS

\author{
A total of \\ 337 patients \\ were \\ randomized \\ to ARI + \\ $\mathrm{LI} / \mathrm{VAL}(\mathrm{n}=$ \\ 168) or PLB \\ $+\mathrm{LI} / \mathrm{VAL}(\mathrm{n}$ \\ = 169).

$x^{2}+x^{2}$
The Kaplan-Meier relapse rate at 52 weeks was $17 \%$ with ARI + LI/VAL and 29\% with PLB + LI/VAL; hazard ratio $=0.54$ (95\% Cl: 0.33-0.89; log-rank $p=0.014$ )

The most common AE $\geq 5 \%(A R I+L I / V A L$ vs. PLB + LI/VAL) were headache (13.2\% vs. $10.8 \%$ ), weight increase $(9.0 \%$ vs. $6.6 \%)$, tremor (6.0\% vs. $2.4 \%)$, and insomnia (5.4\% vs. $9.6 \%)$.

In total, 283

DB with open label extension. BD patients with manic or mixed episodes were treated with open-label LI or VAL. Vieta, et Those with inadequate

al., 2010 [38] response were randomized to $A R I+$ LI/VAL or PLB + LI/VAL for 6 weeks in a DB manner. Completers of the 6-week DB trial could enter a 46-week extension with open-label $A R I$ + LI or ARI + VAL.
$(A R I+L I n=$ 108; ARI + VAL $\mathrm{n}=$ 175) patients entered the 46-week open label extension. Out of them, $146(\mathrm{ARI}+$ LI n = 55; $A R I+V A L n$ =91) completed the trial.

total of 161 patients met the stabilization criteria and were
Significant

improvements from baseline over the 52 weeks occurred with $\mathrm{ARI}+\mathrm{LI}$ and ARI + VAL (LOCF). Mean YMRS total score changes ARI + LI 16.5 (95\% Cl; -18.1 to $-14.8)$ and $A R I+V A L$ $-17.6(95 \% \mathrm{Cl} ;-18.9$ to -16.3$)$, both $p<$ 0.001 versus

baseline. Mean

MADRS total score chances ARI + LI -1.7 (95\% Cl; -3.3 to -0.1 , $p<0.05$ versus baseline) and ARI + VAL -2.7 (95\% Cl; 4.0 to $-1.4, p<0.001$ vs. baseline).

At 100 weeks, time to relapse was significantly longer for ARI than PLB (hazard ratio $=0.53[95 \% \mathrm{Cl}=$ (YMRS score $\leq 10$ MADRS score $\leq 13$ for 6 consecutive weeks) were

Keck, et randomized to DB al., treatment with ARI or PLB
0.32 to 0.87$], p=$ 0.011). ARI was superior to PLB in delaying time to manic relapse (hazard ratio
Frequently reported $A E$ with $A R I+L I$ vs. ARI + VAL: tremor (17.0\% vs. $12.1 \%)$, akathisia $(6.6 \%$ vs. $8.6 \%)$, headache (6.6\% vs. $4.0 \%$ ), insomnia (9.4\% vs. $10.3 \%)$, depression $(7.5 \%$ vs. $9.2 \%)$ and weight increase (11.3\% vs. $8.6 \%)$. The majority of new onset akathisia and insomnia occurred early. Mean weight change from DB endpoint to week 46 (LOCF) was 2.3 (0.6) $\mathrm{kg}$ with $\mathrm{ARI}+\mathrm{LI}$ and $2.0(0.4) \mathrm{kg}$ with ARI + VAL.

AE reported during 100 weeks of treatment with ARI versus PLB ( $\geq 5 \%$ incidence and twice placebo rate) were tremor, akathisia, dry mouth, hypertension, weight gain, vaginitis, mood episode

compared with LI or VAL

monotherapy and was relatively well tolerated during the 1-year study period.

These findings suggest that there is long-term benefit in continuing ARI adjunctive to MS after sustained remission is achieved.

Long-term ARI adjunctive to LI/VAL in bipolar mania was safe and well tolerated. Improvements in manic symptoms and functioning were maintained. $A R I$, adjunctive to either LI or VAL appeared to be equally safe and effective combinations for the treatment of BD.

Over a 100-week treatment period, ARI monotherapy was effective for relapse prevention of manic or mixed episodes in BD patients who 


\section{Cureus}

2007

[23]

\author{
for 26 weeks. The primary \\ endpoint was time to \\ relapse for any mood \\ episode. Patients who \\ completed the 26-week \\ stabilization and \\ maintained remission \\ were continued in a $\mathrm{DB}$ \\ manner with ARI or PLB \\ for an additional 74 \\ weeks.
}

$\begin{array}{lll}\text { randomly } & =0.35[95 \% \mathrm{Cl}=0.16 & \text { abnormal thinking, } \\ \text { assigned to } & \text { to } 0.75], p=0.005) . & \text { pharyngitis, and flu } \\ \text { ARI }(\mathrm{n}=78) & \text { However, no } & \text { syndrome. Mean } \\ \text { and PLB ( } \mathrm{n} & \text { significant differences } & \text { weight change from } \\ =83) . & \text { were observed in time } & \text { baseline to } 100 \text { weeks } \\ & \text { to depressive relapse } & \text { (LOCF) was + 0.4 +/- } \\ & \text { (hazard ratio }=0.81 & 0.8 \mathrm{~kg} \text { with ARI and - } \\ & {[95 \% \mathrm{Cl}=0.36 \text { to }} & 1.9+/-0.8 \mathrm{~kg} \text { with } \\ & 1.81], p=0.602) & \text { PLB. }\end{array}$

randomly

$=0.35[95 \% \mathrm{Cl}=0.16$

pharyngitis, and flu

syndrome. Mean

weight change from

baseline to 100 weeks

(LOCF) was + 0.4 +/

$0.8 \mathrm{~kg}$ with $\mathrm{ARI}$ and -

PLB. were initially

stabilized on ARI

for 6 consecutive

weeks. ARI

maintained a

good safety and

tolerability profile

during the $100-$

week trial period.

\section{TABLE 3: Key Long-Term Aripiprazole Studies in Mania}

Abbreviations: AE - adverse events, ARI - aripiprazole, BD - bipolar disorder, $\mathrm{Cl}$ - confidence interval, DB - double blind, $\mathrm{LI}$ - lithium, LOCF - last observation carried forward, MADRS - Montgomery-Asberg Depression Rating Scale, PLB - placebo, VAL - valproate, YMRS - Young Mania Rating Scale

Maintenance Study in Patients with Initial Manic or Mixed Episode

A 100-week aripiprazole monotherapy study was conducted in a placebo-controlled, doubleblind style to assess the safety and efficacy of the drug in preventing relapse of mood episodes in Bipolar I disorder patients. Bipolar subjects with a recent manic or mixed episode received open-label aripiprazole, 15 or $30 \mathrm{mg}$ per day, for six to 18 weeks. Patients achieving stabilization (YMRS score $\leqslant 10$, MADRS score $\leqslant 13$ for six consecutive weeks) entered the double-blind phase, at which point they were randomly assigned to treatment with aripiprazole or placebo for 26 weeks. The primary endpoint was time to relapse for any mood episode. Patients who remained in remission during the 26-week stabilization period continued in a double-blind fashion with aripiprazole or placebo for an additional 74 weeks and were monitored for relapse, efficacy, and tolerability. In total, 161 patients met the stabilization criteria and were randomly assigned to aripiprazole $(\mathrm{N}=78)$ or placebo $(\mathrm{N}=83)$. At 100 weeks, time to relapse was significantly longer with aripiprazole than placebo; the active drug was superior to placebo in delaying time to manic relapse. However, no significant differences were observed in time to depressive relapse. Adverse events for aripiprazole occurring in more than $5 \%$ of the subjects included tremor, akathisia, dry mouth, flu syndrome, and mild weight gain, among others. In conclusion, over a 100-week treatment period, aripiprazole monotherapy was effective for manic relapse prevention and maintained a good safety and tolerability profile [23]. In a post-hoc analysis of the 100-week maintenance study, patients with rapid cycling were identified and efficacy of aripiprazole monotherapy versus placebo was examined. In this group of cases, the active drug was statistically superior to no therapy in preventing affective recurrences in an otherwise recalcitrant manifestation of BD [42].

\section{Clinical Implications of Acute and Long-term Aripiprazole Studies in Bipolar Mania}

In view of the efficacy and safety data presented above, aripiprazole should be considered a first-line agent in the treatment of manic or mixed episodes in Bipolar I disorder patients. It can be preferentially administered in both new onset and recurrent mania, either as monotherapy or as an add-on to mood stabilizers, and may be used favorably in the acute and maintenance phases with the manic polarity of illness. Further, when patients experiencing a manic or mixed episode have less than optimal response to monotherapy with conventional 
mood stabilizers, aripiprazole is a valid choice as an adjunctive medication to induce remission.

Akin to schizophrenia, it is a switch option in bipolar patients who poorly put up with other antipsychotics due to side effects and should be preferred in the long term treatment of such cases to promote compliance. As demonstrated in acute and long-term RCTs, it has notably few adverse effects and is well tolerated as mono and adjunctive therapy, with lower discontinuation rates as compared to typical antipsychotics, for example, haloperidol. It should be used in preference to agents like olanzapine in patients with high body mass index, dyslipidemia, and glucose intolerance. When a metabolic syndrome is induced during the ongoing treatment of bipolar subjects with other SGAs, aripiprazole is a valid alternate medication. Correspondingly, it can be utilized as a switch option in patients who develop hyperprolactinemia, EPSE, QTc prolongation, drowsiness, and sedation with the use of either typical or second generation antipsychotics in the course of treatment of BD.

\section{Third generation antipsychotics in the treatment of bipolar depression}

Although the distinctive clinical feature of bipolar disorder is the abnormally elevated mood seen in manic exacerbations, it does not usually make up the most common affective state of the patients. The majority of bipolar patients spend much more time suffering from depressive manifestations, which may present as major depressive episodes, sub-syndromal symptoms, or mixed episodes [43]. Depressive states are often comorbid with other neuropsychiatric conditions like anxiety spectrum disorders and are the major source of morbidity and mortality in BD. Depressive symptoms frequently show resistance to the usual mood stabilizers and are incriminated in refractoriness and chronicity of the illness. Used either as monotherapy or adjunctively to mood stabilizers, third generation antipsychotics are emerging as a credible treatment option for bipolar depression. The latest positive published trial in this respect is with cariprazine, a novel antipsychotic that acts as a partial agonist at D2R and D3R and, like aripiprazole and brexpiprazole, is a multipurpose psychotherapeutic agent [44]. The next three sections evaluate the data regarding the efficacy of aripiprazole in the acute treatment and prophylaxis of bipolar depression.

\section{Randomized, Controlled Trials of Aripiprazole in Bipolar I Depression}

Two matching eight-week, multicenter RCTs with placebo control (CN 138-096 [Study 1] and CN 138-146 [Study 2]) were carried out to assess the efficacy and safety of aripiprazole in outpatients with Bipolar I disorder experiencing a major depressive episode without psychotic features. Patients were randomized to placebo or aripiprazole started at $10 \mathrm{mg}$ per day, then dosed in a versatile style at $5-30 \mathrm{mg} / \mathrm{d}$ based on clinical effect and tolerability. The main end point was mean change from baseline to Week 8 in the MADRS total score. The last observation carried forward was utilized to statistically account for subjects who dropped out of the trials prematurely. In Studies 1 and 2, respectively, 186 and 187 patients were randomized to aripiprazole, and 188 and 188 to placebo. Although numerically significant distinctions were detected during Weeks 1 to 6 , aripiprazole did not pull off statistical meaning versus placebo at Week 8 in either study. This was made evident as an inconsequential reduction in MADRS total score from the baseline, which was the most important outcome measure. The key secondary endpoint was the Clinical Global Impressions Bipolar Version Severity of Illness-Depression score, and although the active agent showed initial statistical parting, it was not found to be better than placebo at Week 8 in this measure either. Aripiprazole was associated with a higher incidence of akathisia, insomnia, nausea, fatigue, restlessness, and dry mouth versus placebo. More patients stopped taking aripiprazole versus placebo in Study 1 (46.8\% vs. $35.1 \%)$ and Study 2 (41.2\% vs. $29.8 \%)$. Aripiprazole monotherapy, as dosed in this design, was not significantly more effective than placebo in the treatment of bipolar depression at study end point of Week 8 [45]. 
In the management of acute episodes in a major depressive disorder, aripiprazole is an established treatment as an add-on to standard antidepressants. However, this is not the case with acute bipolar depression as demonstrated in an RCT in which aripiprazole failed to separate from placebo on the primary efficacy measure of Hamilton Rating Scale for Depression when used with open adjunctive citalopram [46].

Post-hoc Analysis of Data from Aripiprazole Monotherapy Trials in Acute Bipolar I Depression

A pooled, post-hoc examination of data from the above-mentioned two randomized, controlled trials was undertaken and the outcome of aripiprazole monotherapy versus placebo was assessed based on the initial severity of depressive symptoms of the study subjects. This was achieved by categorizing cases as severely (Bech-6 total score $>15$ ) or less severely depressed (Bech-6 total score < 15) using sub-sets of Bech-Rafaelsen scale. Efficacy was measured by mean variations in MADRS total and MADRS- 6 subscale scores from the initiation of the trials to the endpoint at Week 8 using a mixed model, repeated measures analysis. In this manner, a sum of 133 patients $(n=62$ on the active drug) was found to be severely depressed and 612 patients ( $n=309$ on aripiprazole) as less severely depressed. At Week 8 , the mean MADRS total score reduction for severely depressed patients receiving aripiprazole compared with placebo was -19.4 vs. $-15.4(p=0.14)$, whereas MADRS-6 subscale score reduction for patients receiving aripiprazole compared with placebo was -13.8 vs. $-10.3(p=0.07)$. Adverse event profiles were similar between the two severity groups. The sum of the analysis was that improvement in essential depressive symptoms occurred with flexibly dosed aripiprazole monotherapy in subjects with more severe major depressive episodes than those with less severe manifestations in Bipolar I disorder [47].

\section{Prevention of Depressive Relapse}

Compared to placebo, aripiprazole monotherapy was shown in a maintenance study to delay time to manic relapse but not for depressive relapse after 26 and 100 weeks of treatment [23]. The inability of aripiprazole to reduce the time to depressive relapse in this study could be due to the enrollment of patients with index manic/mixed episodes, a manic polarity of illness, and consequently, lower occurrence of depressive relapses. Another long-term trial comparing aripiprazole and lithium in a head-to-head manner showed that both drugs were equally efficacious in preventing affective recurrences of manic and mixed type but the former agent did not obviate depressive relapses [41]. A 52-week trial comparing aripiprazole or placebo adjunctive to conventional mood stabilizers showed that the active drug, plus lithium or divalproex, was more effective in manic than depressive relapse prevention [22]. Although data does not support the efficacy of aripiprazole in precluding depressive relapses, there is a need for more and better-designed studies in this regard. One strategy may be to enroll bipolar patients with index depressive episodes in long-term aripiprazole trials, either as monotherapy or in conjunction with mood stabilizers. Further, when proposing protocols for novel psychotherapeutic agents in bipolar depression, exclusive reliance on efficacy measures like MADRS may not portray the whole picture. There is also an argument for including other parameters that assess general functioning, reduction in comorbidities, and decline in overall symptomatic burden [48]. It must not be forgotten that $\mathrm{BD}$ is linked to numerous comorbidities, chief among which are substance use disorders and anxiety spectrum conditions. Aripiprazole is a multifunction drug, and in addition to targeting core affective symptoms, it has important implications for the treatment of associated neuropsychiatric comorbidities in bipolar spectrum disorders. 


\section{Cureus}

MDD is a major psychiatric ailment and shares phenotypic, pathophysiologic, and prognostic characteristics with bipolar disorder. It is a recurrent condition and is often refractory to treatment with the usual antidepressant medications, resulting in continued morbidity in spite of optimal therapy with the latter agents. In this event, there is an enduring need for psychotherapeutic drugs, which are truly efficacious in MDD and can stall the vicious cycle of deterioration in the biopsychosocial domains. RCTs of aripiprazole have been conducted in this disorder, mainly as an adjunct to first-line antidepressants and salutary affects statistically demonstrated with standardized measures [49]. This is of significance, as MDD is a recalcitrant condition with neuroprogressive features, and aripiprazole, being the prototypical third generation antipsychotic, has opened fresh avenues in the overall treatment of this disorder.

\section{New directions and emerging therapies for bipolar and related disorders}

Partial agonism, functional selectivity, and serotonin-dopamine activity modulation are the new pharmacodynamic principles in the treatment of major psychiatric disorders, including bipolar spectrum disorders. In the case of aripiprazole, evidence from controlled trials supports its usefulness in acute manic and mixed episodes, rapid cycling, psychotic mania, and prevention of manic recurrences in Bipolar I disorder. It is an FDA approved therapy for schizophrenia and adjunctive treatment of MDD, which expounds the fact that aripiprazole is a versatile psychotherapeutic agent. As a further advancement in drug development, two new related compounds, brexpiprazole and cariprazine, have won FDA endorsement, while a number of other molecules are in different stages of experimentation. These are the latest "third generation antipsychotics" which are, in essence, multipurpose medications and have the promise of alleviating hitherto recalcitrant manifestations like cognitive and negative deficits associated with neuroprogressive psychiatric disorders [50]. As the deficit symptoms are responsible for the true burden of principal psychiatric diseases, the recent paradigm shift in pharmacotherapy is opening fresh avenues in the treatment of these conditions. It is beyond the scope of this manuscript to go into the details of published RCTs and ongoing studies of brexpiprazole and cariprazine, but novel antipsychotics hold the potential of improving the overall prognosis of patients with major psychiatric ailments. Table 4 gives FDA approved indications of aripiprazole, brexpiprazole, and cariprazine at the time of the writing of this manuscript. Figure 4 illustrates the therapeutic prospects of this group of medications.

\begin{tabular}{|c|c|c|c|}
\hline Indications & Aripiprazole & Brexpiprazole & Cariprazine \\
\hline Schizophrenia & Yes & Yes & Yes \\
\hline Manic/mixed episodes of Bipolar I disorder & Yes & No & Yes \\
\hline Maintenance treatment of Bipolar I disorder & Yes, as an adjunct to MS & No & No \\
\hline Bipolar I depression & No (negative RCT) & No & No (positive RCT) \\
\hline MDD & Yes, as an adjunct & Yes, as an adjunct & No \\
\hline
\end{tabular}

\section{TABLE 4: FDA Approved Indications of Aripiprazole, Brexpiprazole and Cariprazine}

Abbreviations: FDA - Food and Drug Administration; MDD - major depressive disorder; MS - mood stabilizers; RCT - randomized controlled trial 


\section{Cureus}

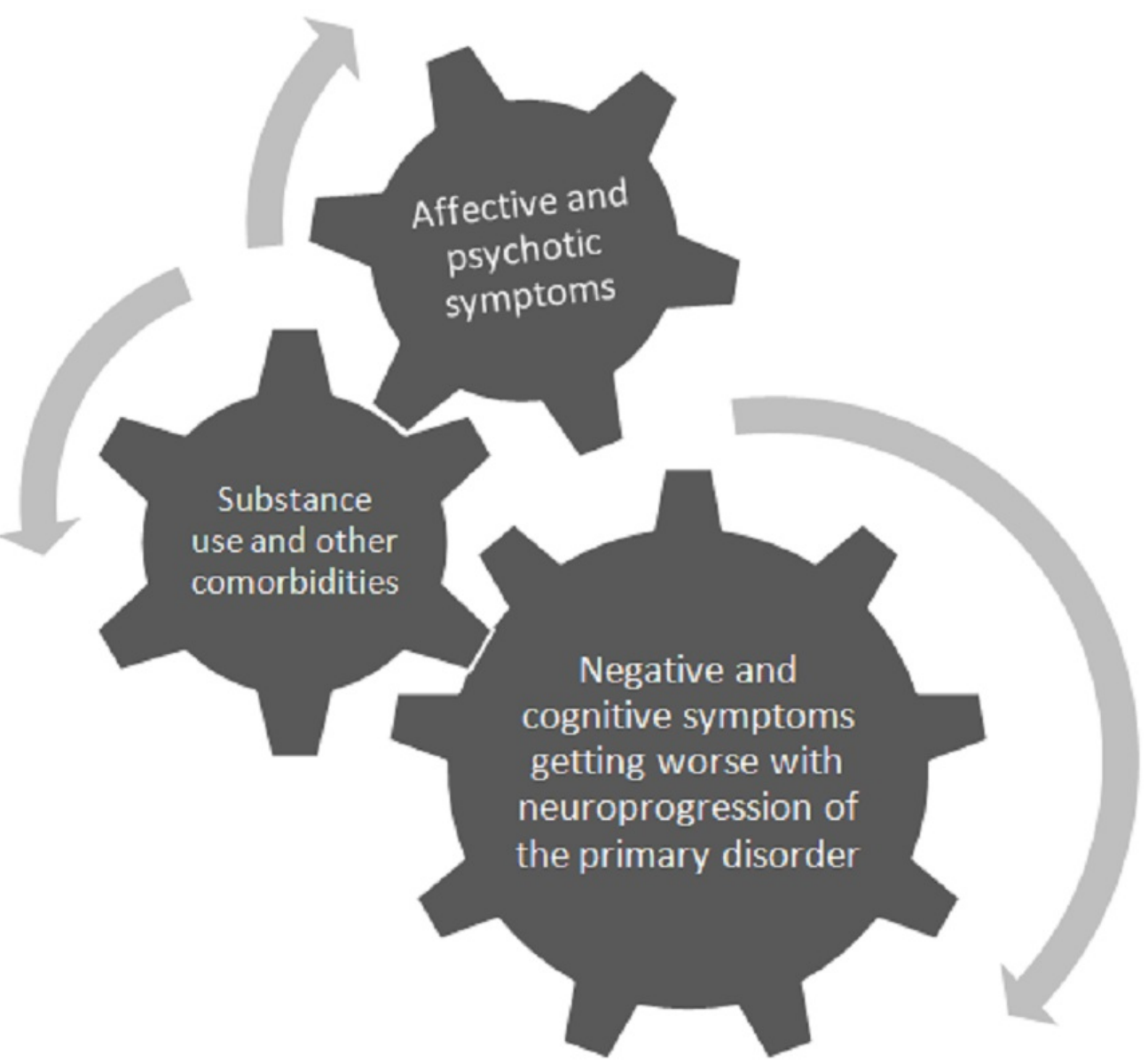

\section{FIGURE 4: Targeting neuropsychiatric symptoms in major mental disorders}

Principal psychiatric disorders share the common feature of neuroprogression, which implies that there is increasing biopsychosocial impairment as the illness advances. Novel agents like aripiprazole, brexpiprazole, and cariprazine have the potential to treat various disease manifestations and be of value in affective, psychotic, cognitive, and negative symptoms.

\section{Conclusions}

Bipolar disorder is a highly disabling condition with a large number of patients remaining symptomatic either because they are refractory to the traditional mood-stabilizing medications or cannot tolerate these due to adverse effects. There is a pressing need for new and better drugs, which are efficacious in treating as well as preventing mood episodes in these patients. Aripiprazole is the first among the unique group of novel antipsychotics that is well studied in all phases of $\mathrm{BD}$ and controlled trials have been very helpful in delineating its place in the treatment of this chronic, life-long disorder. It is particularly efficacious in managing patients with the manic polarity of illness and is safe and well tolerated by the majority of treated subjects. Although controlled trials have not proven its worth in acute or recurrent bipolar depression, it may have a place in treating bipolar spectrum disorder patients with substance use and other comorbidities. Currently, it is highly recommended for the management of acute and recurrent mania in Bipolar I disorder. The same appears to be true for mixed episodes, rapid cycling, and psychotic mania. Considering its value in the treatment of anxiety spectrum and addictive disorders, it can be efficacious in bipolar subjects with these concomitant conditions. It is also the preferred agent in patients with metabolic abnormalities and those who are 
intolerant of other antipsychotics due to the latter's side effect load.

\section{Additional Information \\ Disclosures}

Conflicts of interest: In compliance with the ICMJE uniform disclosure form, all authors declare the following: Payment/services info: All authors have declared that no financial support was received from any organization for the submitted work. Financial relationships: All authors have declared that they have no financial relationships at present or within the previous three years with any organizations that might have an interest in the submitted work. Other relationships: All authors have declared that there are no other relationships or activities that could appear to have influenced the submitted work.

\section{References}

1. Judd LL, Akiskal HS: The prevalence and disability of bipolar spectrum disorders in the US population: re-analysis of the ECA database taking into account subthreshold cases. J Affect Disord. 2003, 73:123-31. 10.1016/S0165-0327(02)00332-4

2. Fagiolini A, Forgione R, Maccari M, Cuomo A, Morana B, Dell'Osso MC, Pellegrini F, Rossi A: Prevalence, chronicity, burden and borders of bipolar disorder . J Affect Disord. 2013, 148:16169. 10.1016/j.jad.2013.02.001

3. Zimmerman M, Morgan TA: Problematic boundaries in the diagnosis of bipolar disorder: the interface with borderline personality disorder. Curr Psychiatry Rep. 2013, 15:422. 10.1007/s11920-013-0422-z

4. Latalova K, Kamaradova D, Prasko J: Suicide in bipolar disorder: a review . Psychiatr Danub. 2014, 26:108-14.

5. Altamura AC, Dragogna F: Should the term 'antipsychotic' be changed to 'multidimensional stabiliser' in bipolar disorder? Towards a new denomination for 'atypical antipsychotics'. Aust N Z J Psychiatry. 2013, 47:707-709. 10.1177/0004867413492572

6. Muneer A: Pharmacotherapy of bipolar disorder with quetiapine: a recent literature review and an update. Clin Psychopharmacol Neurosci. 2015, 13:25-35. 10.9758/cpn.2015.13.1.25

7. Veselinović T, Paulzen M, Gründer G: Cariprazine, a new, orally active dopamine D2/3 receptor partial agonist for the treatment of schizophrenia, bipolar mania and depression. Expert Rev Neurother. 2013, 13:1141-59. 10.1586/14737175.2013.853448

8. Mailman RB, Murthy V: Third generation antipsychotic drugs: partial agonism or receptor functional selectivity?. Curr Pharm Des. 2010, 16:488-501.

9. de Bartolomeis A, Tomasetti C, Iasevoli F: Update on the mechanism of action of aripiprazole: translational insights into antipsychotic strategies beyond dopamine receptor antagonism. CNS Drugs. 2015, 29:773-99. 10.1007/s40263-015-0278-3

10. Chen X, Sassano MF, Zheng L, Setola V, Chen M, Bai X, Frye SV, Wetsel WC, Roth BL, Jin J: Structure-functional selectivity relationship studies of $\beta$-arrestin-biased dopamine $\mathrm{D}_{2}$ receptor agonists. J Med Chem. 2012, 55:7141-53. 10.1021/jm300603y

11. Maeda K, Lerdrup L, Sugino H, Akazawa H, Amada N, McQuade RD, Stensbol TB, Bundgaard C, Arnt J, Kikuchi T: Brexpiprazole II: antipsychotic-like and procognitive effects of a novel serotonin-dopamine activity modulator. J Pharmacol Exp Ther. 2014, 350:605-14. 10.1124/jpet.114.213819

12. Mallikaarjun S, Salazar DE, Bramer SL: Pharmacokinetics, tolerability, and safety of aripiprazole following multiple oral dosing in normal healthy volunteers. J Clin Pharmacol. 2004, 44:179-87. 10.1177/0091270003261901

13. Suzuki T, Mihara K, Nakamura A, Kagawa S, Nagai G, Nemoto K, Kondo T: Effects of genetic polymorphisms of CYP2D6, CYP3A5, and ABCB1 on the steady-state plasma concentrations of aripiprazole and its active metabolite, dehydroaripiprazole, in Japanese patients with schizophrenia. Ther Drug Monit. 2014, 36:651-55. 10.1097/FTD.0000000000000070

14. Pan B, Chen J, Lian J, Huang XF, Deng C: Unique effects of acute aripiprazole treatment on the dopamine D2 receptor downstream cAMP-PKA and Akt-GSK3 $\beta$ signalling pathways in rats. PLoS One. 2015, 10:e0132722. 10.1371/journal.pone.0132722 
15. Han M, Huang XF, Deng C: Aripiprazole differentially affects mesolimbic and nigrostriatal dopaminergic transmission: implications for long-term drug efficacy and low extrapyramidal side-effects. Int J Neuropsychopharmacol. 2009, 12:941-52. 10.1017/S1461145709009948

16. Latapy C, Beaulieu JM: $\beta$-Arrestins in the central nervous system. Prog Mol Biol Transl Sci. 2013, 118:267-95. 10.1016/B978-0-12-394440-5.00011-5

17. Park SM, Chen M, Schmerberg CM, Dulman RS, Rodriguiz RM, Caron MG, Jin J, Wetsel WC: Effects of $\beta$-arrestin-biased dopamine D2 receptor ligands on schizophrenia-like behavior in hypoglutamatergic mice. Neuropsychopharmacology. 2016, 41:704-15. 10.1038/npp.2015.196

18. Yoshimi N, Fujita Y, Ohgi Y, Futamura T, Kikuchi T, Hashimoto K: Effects of brexpiprazole, a novel serotonin-dopamine activity modulator, on phencyclidine-induced cognitive deficits in mice: a role for serotonin 5-HT1A receptors. Pharmacol Biochem Behav. 2014, 124:245-49. 10.1016/j.pbb.2014.06.008

19. Keck PE Jr, Marcus R, Tourkodimitris S, Ali M, Liebeskind A, Saha A, Ingenito G; Aripiprazole Study Group: A placebo-controlled, double-blind study of the efficacy and safety of aripiprazole in patients with acute bipolar mania. Am J Psychiatry. 2003, 160:1651-58. 10.1176/appi.ajp.160.9.1651

20. Sachs G, Sanchez R, Marcus R, Stock E, McQuade R, Carson W, Abou-Gharbia N, Impellizzeri C, Kaplita S, Rollin L, Iwamoto T; Aripiprazole Study Group: Aripiprazole in the treatment of acute manic or mixed episodes in patients with bipolar I disorder: a 3-week placebocontrolled study. J Psychopharmacol. 2006, 20:536-46. 10.1177/0269881106059693

21. Vieta E, T'joen C, McQuade RD, Carson WH Jr, Marcus RN, Sanchez R, Owen R, Nameche L: Efficacy of adjunctive aripiprazole to either valproate or lithium in bipolar mania patients partially nonresponsive to valproate/lithium monotherapy: a placebo-controlled study. Am J Psychiatry. 2008, 165:1316-25. 10.1176/appi.ajp.2008.07101560

22. Marcus R, Khan A, Rollin L, Morris B, Timko K, Carson W, Sanchez R: Efficacy of aripiprazole adjunctive to lithium or valproate in the long-term treatment of patients with bipolar I disorder with an inadequate response to lithium or valproate monotherapy: a multicenter, double-blind, randomized study. Bipolar Disord. 2011, 13:133-44. 10.1111/j.13995618.2011.00898.x

23. Keck PE Jr, Calabrese JR, McIntyre RS, McQuade RD, Carson WH, Eudicone JM, Carlson BX, Marcus RN, Sanchez R; Aripiprazole Study Group: Aripiprazole monotherapy for maintenance therapy in bipolar I disorder: a 100-week, double-blind study versus placebo. J Clin Psychiatry. 2007, 68:1480-91.

24. Newcomer JW: Second-generation (atypical) antipsychotics and metabolic effects: a comprehensive literature review. CNS Drugs. 2005, 19:1-93. 10.2165/00023210-20051900100001

25. Kemp DE, Calabrese JR, Tran QV, Pikalov A, Eudicone JM, Baker RA: Metabolic syndrome in patients enrolled in a clinical trial of aripiprazole in the maintenance treatment of bipolar I disorder: a post hoc analysis of a randomized, double-blind, placebo-controlled trial. J Clin Psychiatry. 2010, 71:1138-44. 10.4088/JCP.09m05159gre

26. Dhillon S: Aripiprazole: a review of its use in the management of mania in adults with bipolar I disorder. Drugs. 2012, 72:133-62. 10.2165/11208320-000000000-00000

27. Kanba S, Kawasaki H, Ishigooka J, Sakamoto K, Kinoshita T, Kuroki T: A placebo-controlled, double-blind study of the efficacy and safety of aripiprazole for the treatment of acute manic or mixed episodes in Asian patients with bipolar I disorder (the AMAZE study). World J Biol Psychiatry. 2014, 15:113-21. 10.3109/15622975.2012.669047

28. El Mallakh RS, Vieta E, Rollin L, Marcus R, Carson WH, McQuade R: A comparison of two fixed doses of aripiprazole with placebo in acutely relapsed, hospitalized patients with bipolar disorder I (manic or mixed) in subpopulations (CN138-007). Eur Neuropsychopharmacol. 2010, 20:776-83. 10.1016/j.euroneuro.2010.07.003

29. Young AH, Oren DA, Lowy A, McQuade RD, Marcus RN, Carson WH, Spiller NH, Torbeyns AF, Sanchez R: Aripiprazole monotherapy in acute mania: 12-week randomised placebo- and haloperidol-controlled study. Br J Psychiatry. 2009, 194:40-48. 10.1192/bjp.bp.108.049965

30. Keck PE, Orsulak PJ, Cutler AJ, Sanchez R, Torbeyns A, Marcus RN, McQuade RD, Carson WH; CN138-135 Study Group: Aripiprazole monotherapy in the treatment of acute bipolar I mania: a randomized, double-blind, placebo- and lithium-controlled study. J Affect Disord. 2009, 112:36-49. 10.1016/j.jad.2008.05.014

31. Vieta E, Bourin M, Sanchez R, Marcus R, Stock E, McQuade R, Carson W, Abou-Gharbia, 
Swanink R, Iwamoto T: Effectiveness of aripiprazole v. haloperidol in acute bipolar mania: double-blind, randomised, comparative 12-week trial. Br J Psychiatry. 2005, 187:235-42. 10.1192/bjp.187.3.235

32. Jeong HG, Lee MS, Ko YH, Han C, Jung IK: Combination treatment with aripiprazole and valproic acid for acute mania: an 8-week, single-blind, randomized controlled trial. Clin Neuropharmacol. 2012, 35:97-102. 10.1097/WNF.0b013e3182560401

33. Findling RL, Nyilas M, Forbes RA, McQuade RD, Jin N, Iwamoto T, Ivanova S, Carson WH, Chang K: Acute treatment of pediatric bipolar I disorder, manic or mixed episode, with aripiprazole: a randomized, double-blind, placebo-controlled study. J Clin Psychiatry. 2009, 70:1441-51. 10.4088/JCP.09m05164yel

34. Suppes T, Eudicone J, McQuade R, Pikalov A 3rd, Carlson B: Efficacy and safety of aripiprazole in subpopulations with acute manic or mixed episodes of bipolar I disorder. J Affect Disord. 2008, 107:145-54. 10.1016/j.jad.2007.08.015

35. Meduri M, Gregoraci G, Baglivo V, Balestrieri M, Isola M, Brambilla P: A meta-analysis of efficacy and safety of aripiprazole in adult and pediatric bipolar disorder in randomized controlled trials and observational studies. J Affect Disord. 2016, 191:187-208. 10.1016/j.jad.2015.11.033

36. Keck PE Jr, Calabrese JR, McQuade RD, Carson WH, Carlson BX, Rollin LM, Marcus RN, Sanchez R; Aripiprazole Study Group: A randomized, double-blind, placebo-controlled 26week trial of aripiprazole in recently manic patients with bipolar I disorder. J Clin Psychiatry. 2006, 67:626-37.

37. Yatham LN, Fountoulakis KN, Rahman Z, Ammerman D, Fyans P, Marler SV, Baker RA, Carlson BX: Efficacy of aripiprazole versus placebo as adjuncts to lithium or valproate in relapse prevention of manic or mixed episodes in bipolar I patients stratified by index manic or mixed episode. J Affect Disord. 2013, 147:365-72. 10.1016/j.jad.2012.11.042

38. Vieta E, Owen R, Baudelet C, McQuade RD, Sanchez R, Marcus RN: Assessment of safety, tolerability and effectiveness of adjunctive aripiprazole to lithium/valproate in bipolar mania: a 46-week, open-label extension following a 6-week double-blind study. Curr Med Res Opin. 2010, 26:1485-96. 10.1185/03007991003779380

39. Woo YS, Bahk WM, Chung MY, Kim DH, Yoon BH, Lee JH, Ahn YM, Chung SK, Kim JG, Lee KH, Paik KC: Aripiprazole plus divalproex for recently manic or mixed patients with bipolar I disorder: a 6-month, randomized, placebo-controlled, double-blind maintenance trial. Hum Psychopharmacol. 2011, 26:543-53. 10.1002/hup.1240

40. Carlson BX, Ketter TA, Sun W, Timko K, McQuade RD, Sanchez R, Vester-Blokland E, Marcus $\mathrm{R}$ : Aripiprazole in combination with lamotrigine for the long-term treatment of patients with bipolar I disorder (manic or mixed): a randomized, multicenter, double-blind study (CN138392). Bipolar Disord. 2012, 14:41-53. 10.1111/j.1399-5618.2011.00974.X

41. El-Mallakh RS1, Marcus R, Baudelet C, McQuade R, Carson WH, Owen R: A 40-week doubleblind aripiprazole versus lithium follow-up of a 12-week acute phase study (total 52 weeks) in bipolar I disorder. J Affect Disord. 2012, 136:258-66. 10.1016/j.jad.2011.11.043

42. Muzina DJ, Momah C, Eudicone JM, Pikalov A, McQuade RD, Marcus RN, Sanchez R, Carlson BX: Aripiprazole monotherapy in patients with rapid-cycling bipolar I disorder: an analysis from a long-term, double-blind, placebo-controlled study. Int J Clin Pract. 2008, 62:679-87. 10.1111/j.1742-1241.2008.01735.x

43. Vieta E, Valenti M: Pharmacological management of bipolar depression: acute treatment, maintenance, and prophylaxis. CNS Drugs. 2013, 27:515-29. 10.1007/s40263-013-0073-y

44. Durgam S, Earley W, Lipschitz A, Guo H, Laszlovszky I, Németh G, Vieta E, Calabrese JR, Yatham LN: An 8-week randomized, double-blind, placebo-controlled evaluation of the safety and efficacy of cariprazine in patients with bipolar in depression. Am J Psychiatry. 2016, 173:271-81. 10.1176/appi.ajp.2015.15020164

45. Thase ME, Jonas A, Khan A, Bowden CL, Wu X, McQuade RD, Carson WH, Marcus RN, Owen R: Aripiprazole monotherapy in nonpsychotic bipolar I depression: results of 2 randomized, placebo-controlled studies. J Clin Psychopharmacol. 2008, 28:13-20. 10.1097/jcp.0b013e3181618eb4

46. Quante A, Zeugmann S, Luborzewski A, Schommer N, Langosch J, Born C, Anghelescu I, Wolf $\mathrm{J}$ : Aripiprazole as adjunct to a mood stabilizer and citalopram in bipolar depression: a randomized placebo-controlled pilot study. Hum Psychopharmacol. 2010, 25:126-32. 10.1002/hup.1096 


\section{Cureus}

47. Thase ME, Bowden CL, Nashat M, Eudicone JM, Marcus R, McQuade RD, Carlson BX: Aripiprazole in bipolar depression: a pooled, post-hoc analysis by severity of core depressive symptoms. Int J Psychiatry Clin Pract. 2012, 16:121-31. 10.3109/13651501.2011.632680

48. Yatham LN, Vieta E, Goodwin GM, Bourin M, de Bodinat C, Laredo J, Calabrese J: Agomelatine or placebo as adjunctive therapy to a mood stabilizer in bipolar I depression: randomized, double-blind placebo-controlled trial. Br J Psychiatry. 2016, 208:78-86. 10.1192/bjp.bp.114.147587

49. Marcus RN, McQuade RD, Carson WH, Hennicken D, Fava M, Simon JS, Trivedi MH, Thase ME, Berman RM: The efficacy and safety of aripiprazole as adjunctive therapy in major depressive disorder: a second multicenter, randomized, double-blind, placebo-controlled study. J Clin Psychopharmacol. 2008, 28:156-65. 10.1097/JCP.0b013e31816774f9

50. Werner FM, Coveñas R: New developments in the management of schizophrenia and bipolar disorder: potential use of cariprazine. Ther Clin Risk Manag. 2015, 11:1657-61.

10.2147/TCRM.S64915 